\title{
Corneal and lens densitometry in patients with vernal keratoconjunctivitis
}

\author{
Yusuf Cem Yılmaz • Sefik Can Ipek • Muhammet Derda Ozer $\mathbb{C}$
}

Received: 22 September 2020/ Accepted: 16 March 2021 / Published online: 22 March 2021

(C) The Author(s), under exclusive licence to Springer Nature B.V. 2021

\begin{abstract}
Aim To evaluate corneal and crystalline lens densitometry in patients with vernal keratoconjunctivitis (VKC).

Methods This is a case-control study. Patients with VKC and age-gender-matched healthy controls underwent a complete ophthalmologic examination with corneal and crystalline lens densitometry measurements. Additionally, the anterior chamber parameters comprise anterior and posterior $\mathrm{K}_{\text {mean }}$ and astigmatism, anterior chamber depth (ACD), anterior chamber volume (ACV), anterior chamber angle (ACA), pachymeter, and corneal volume (CV). Patients who had clinically grade 0 or grade 1 VKC and with only tarsal conjunctiva involvement during the conductance of the study were included. The variables were compared statistically.

Results One hundred and nine eyes were included in the study, in which fifty-one were in the VKC group. There were 25 males in the VKC group (26 female)
\end{abstract}

Y. C. Yilmaz · S. C. Ipek

Ophthalmology Department, Agri State Hospital, Agr1,

Turkey

e-mail: ycyylmz@gmail.com

S. C. Ipek

e-mail: sefikcanipek@gmail.com

M. D. Ozer $(\bowtie)$

Ophthalmology Department, Faculty of Medicine, Van

Yuzuncu Yil University, Tusba, Van 65080, Turkey

e-mail: muhammetderda@gmail.com and 22 males in the control group ( 36 female). A statistically significant difference was found between the groups in terms of posterior corneal astigmatism $(p=0.02)$. The mean corneal pachymeter, $\mathrm{CV}, \mathrm{ACD}$, $\mathrm{ACA}$, and ACV were similar in both groups $(p=0.63$, $p=0.26, p=0.60, \mathrm{p}=0.41$, and $p=0.32$, respectively). The total mean corneal densitometry in the zones extending from 6 to $10 \mathrm{~mm}$ and 10 to $12 \mathrm{~mm}$ was increased in the VKC group compared to the control group ( $p=0.04$ and $p=0.012$, respectively). The mean crystalline lens was found to be denser in the VKC group compared to the control group ( $8.96 \pm 1.6$ vs. $8.5 \pm 0.57$, respectively, $p=0.04$ ).

Conclusion Posterior corneal astigmatism is increased in VKC cases in comparison with age- and gender-matched controls. The peripheral anterior 6-12 $\mathrm{mm}$ annular corneal zone showed increased corneal densitometry in VKC cases compared to the healthy subjects. Additionally, the lens clarity is found to be decreased subclinically in VKC cases compared to control cases.

Keywords Vernal keratoconjunctivitis - Corneal densitometry · Crystalline lens densitometry · Anterior chamber depth - Anterior chamber volume - Anterior chamber angle $\cdot$ Pachymeter $\cdot$ Corneal volume 


\section{Introduction}

Vernal keratoconjunctivitis (VKC) is an allergic ocular surface disease with a chronic and recurrent course $[1,2]$. VKC is a hypersensitivity reaction characterized by infiltration of the tarsal and limbal conjunctiva with various types of inflammatory cells in response to an unknown triggering pathogen $[1,3,4]$. The incidence of VKC has been reported as $6.5 \%$ in a population-based study [5]. Children and adolescents are most commonly affected [2]. The clinical signs of VKC include a papillary reaction at the upper tarsal conjunctiva and gelatinous hypertrophy at the limbus, along with symptoms of itching, redness, and mucoid discharge $[6,7]$.

Corneal involvement in VKC can have a spectrum ranging from punctate epithelial erosions to shield ulcer and limbal insufficiency [1, 8, 9]. VKC can also lead to peripheral corneal neovascularization and vernal pseudogerontoxon [10]. Presumably due to a combination of recurrent mechanical trauma and chronic inflammation, ectatic corneal diseases, such as keratoconus, are frequently seen (14-27\%) in patients having VKC [11-13].

Confocal microscopy studies have revealed an involvement of the superficial and basal corneal epithelium, along with anterior corneal stroma, in VKC, as well as an association with an increased number of inflammatory cells and decreased corneal nerve density [14]. These structural changes affect backward corneal light scattering in VKC, especially at the central and paracentral regions [15].

Corneal and lens densitometry became popular in recent years to evaluate corneal health in various ocular and systemic disorders. Subclinical corneal and lens densitometry changes were detected in cases with type one-type two diabetes mellitus, rheumatoid arthritis, and Wilson disease [16-19]. A recently published report about corneal clarity changes in VKC patients showed increased corneal, and lens densitometry in VKC cases as the disease's clinical-grade severity worsens [20]. They have found increased corneal densitometry in the peripheral cornea of moderate and severe VKC cases compared to healthy controls, but quiescent patients were not included in the study. Additionally, a heterogeneous group of VKC cases, in terms of limbal, tarsal, and mixed type, were involved in the study. In this context, the peripheral cornea in a homogenous group of VKC cases (Tarsal VKC) has not been evaluated. Therefore, this study aimed to use densitometry to evaluate a group of patients having tarsal VKC to confirm the possibility of a subclinical involvement of the peripheral cornea. Additionally, the anterior chamber parameters and keratometric readings were compared between tarsal VKC patients and healthy controls.

\section{Material and methods}

\section{Study design}

This was a cross-sectional case-control study conducted from March 2020 to May 2020 in a secondary care hospital's ophthalmology department. The institutional research board approval was acquired before the conductance of study (IRB Number: 57212153-000-4579). The study protocol followed the rules of Helsinki declaration. The informed consent was obtained from all participants. In total, 109 subjects were involved in the study, and only the right eyes of the subjects were taken into consideration. Overall, 51 eyes of 51 patients were included in the study group. The control group was composed of 58 age- and gender-matched patients (58 eyes). Only the right eyes were taken into account for the statistical analysis.

The American Academy of Ophthalmology Guidelines was followed during the examination of all patients [21]. All patients were asked about symptoms (fever, cough, etc.) and history of contact with a COVID-19 positive case in the past two to fourteen days before the ophthalmic examination. Patients without any symptoms and suspicious history were examined. The instruments and tonometer tip were cleaned using $70 \%$ alcohol embedded swabs after each patient visit. It was paid attention to wear face masks all the time. The social distance was maintained, and direct contact with patients was minimized. The number of patients in the examination room during the visits was also limited. All patients were examined behind a slit-lamp breath shield.

VKC was diagnosed by two ophthalmologists (Y.C.Y. and S.C.I.), who based their diagnoses on history, signs, symptoms, and clinical findings. The diagnostic criteria were bilateral bulbar conjunctival injection, a papillary reaction on the upper tarsal conjunctiva or at the limbus with associated watery 
and mucoid discharge, and other symptoms (itching, redness, etc.). Spared eyelid margins were a further diagnostic sign for VKC. The VKC was graded according to a previously published method, and only the cases who had grade 0 (quiescent disease) or grade 1 (mild disease) VKC during the study were selected [22].

Patients were included in the study group if they met the following criteria: clinical grade 0 or grade 1 VKC during the conductance of study, only tarsal conjunctiva involvement, medication-free for at least three months, no other ocular problem apart from a refractive error equal to or less than \pm 2.00 diopter as spherical equivalents, no systemic disease, and good Pentacam image quality. Patients who had any of the following conditions were excluded from the study group: ocular surface diseases; ocular media opacities; presence of ectatic disorders (keratoconus, etc.), keratitis, active VKC disease, and limbal or mixed involvement; any history of hereditary, inflammatory or infectious ocular disorders other than VKC (e.g., blepharitis, bacterial conjunctivitis, dacryocystitis, etc.); the presence of corneal scars; use of chronic topical medication; contact lens usage; any history of previous ocular surgery, ocular trauma or uveitis, glaucoma, strabismus, or nystagmus; any history of neurological or systemic diseases; or inability to cooperate with Scheimpflug corneal topography image acquisition. The topical corticosteroid usage at least once during the disease course was determined in all study group patients.

The control group was composed of age- and gender-matched individuals who had undergone a completely normal ophthalmologic examination with 20/20 vision in the Snellen chart. They had no ocular or systemic diseases, and they were medication-free.

A complete ophthalmologic assessment was done in all participants. The best-corrected visual acuity (BCVA) was acquired using the Snellen chart. The anterior segment examination by biomicroscopy, measurement of intraocular pressure (Goldmann applanation tonometry), and the fundus evaluation was subsequently conducted. The Scheimpflug densitometry analysis of both the cornea and crystalline lens, the anterior and posterior $\mathrm{K}_{\text {mean }}$, astigmatism, anterior chamber depth, anterior chamber volume, anterior chamber angle, pachymetry, and corneal volume were measured using the Pentacam HR (Oculus Optikgerate GmbH, Wetzlar, Germany) before dilation in all participants. Finally, a dilated fundoscopic examination was done and found normal in all participants.

Image acquisition

Transparency of the cornea and lens was evaluated using the Scheimpflug tomography camera, which is capable of capturing 25 single-slit images in $2 \mathrm{~s}$ while rotating between 0 and 180 degrees around the eye. All measurements were taken in the same room by the same experienced operator (Y.C.Y.). No ocular measurements that required contact with the ocular surface (e.g., applanation tonometry) were conducted prior to the Scheimpflug image acquisition. Operator-induced errors were minimized by using the device's automatic release mode, and only images with good quality were selected for analysis after three consecutive image acquisitions. Images with low quality due to high reflectivity were excluded from the data analysis. (Any image with red quality classification was excluded.) The images were acquired at the same time of day (10-12 AM) in order to avoid the effect of diurnal alterations in corneal hydration.

Patients underwent corneal densitometry prior to pupillary dilation, followed by crystalline lens densitometry after pupillary dilation. Two drops of $1 \%$ tropicamide were instilled at five minutes intervals to achieve maximum pupillary dilation for proper evaluation of the crystalline lens. Crystalline lens densitometry measurements were taken $45 \mathrm{~min}$ after the instillation of the second drop. Corneal densitometry measurements were taken using a previously established image acquisition method [23]. The corneal apex was located automatically by the program, and the device measured the density of the corneal tissue located within a $12 \mathrm{~mm}$ diameter ring centered on the corneal apex. The backward light scattering degree was quantified by the Pentacam HR using grayscale units (GSU) ranging from 0 to $100 \mathrm{GSU}$, where 0 indicated an absence of corneal haze and 100 indicated a totally opaque cornea. The cornea was also further divided into four concentric zones by the software to measure local corneal density. The central zone was a 2-mm-diameter circle located around the corneal apex. The second zone was shaped as an annulus situated 2-6 $\mathrm{mm}$ peripheral to the central zone. The annulus extending from $6-10 \mathrm{~mm}$ was the third zone. The fourth zone was the outermost zone and extended 
from 10-12 $\mathrm{mm}$. The corneal density at different depths (the anterior at $120 \mu \mathrm{m}$ and the central and the most posterior at $60 \mu \mathrm{m}$ ) was also measured in all corneal zones (Fig. 1). The 3D scan mode was used to measure the density of the lens. The mean densitometry value was calculated for the crystalline lens in
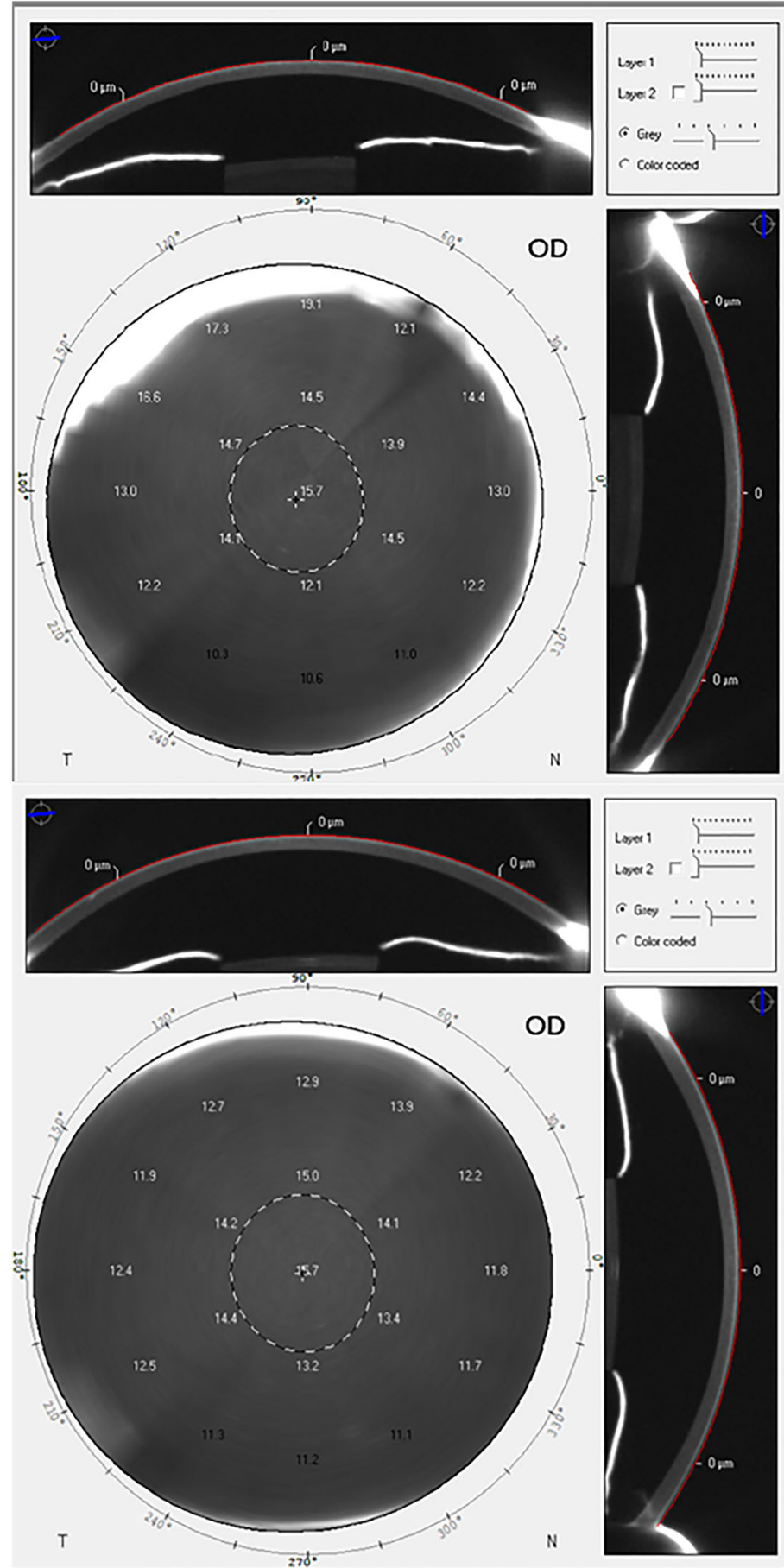

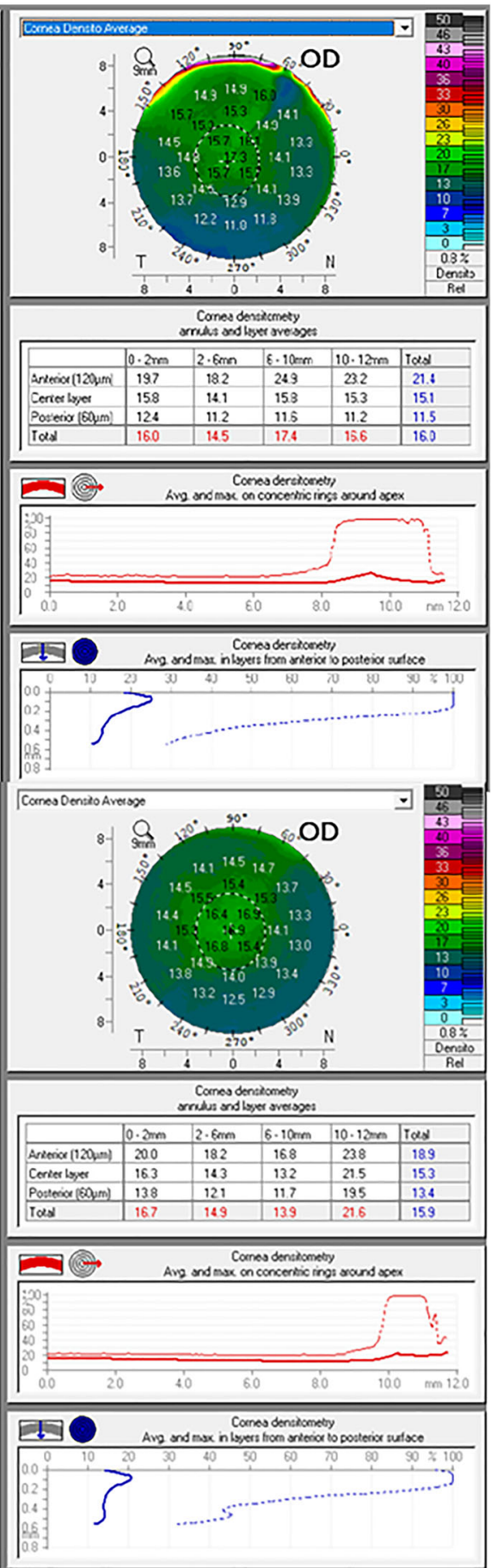

Fig. 1 The corneal densitometry measurement of a patient with VKC (upper figure) and a healthy subject (lower figure) 
three zones located around the pupil center comprising zone $1(2.0 \mathrm{~mm}$ in diameter), zone $2(4.0 \mathrm{~mm}$ in diameter), and zone 3 (6.0 $\mathrm{mm}$ in diameter) (Fig. 2). The mean corneal pachymeter, corneal volume (CV), anterior chamber depth (ACD), anterior chamber angle (ACA), and anterior chamber volume (ACV) were measured with the Pentacam HR in all participants at the same session, and the values were recorded.
Statistical analysis

The Statistical Package for the Social Sciences (SPSS) software version 22 (SPSS Inc., Chicago, IL, USA) was used in statistical analysis. The KolmogorovSmirnov test was used to determine the distribution of the variables. Descriptive variables were addressed as means and standard deviations. The Chi-square test was used to check the gender distribution, and an age comparison was made by using the Mann-Whitney U test between the groups. Comparison of the variables
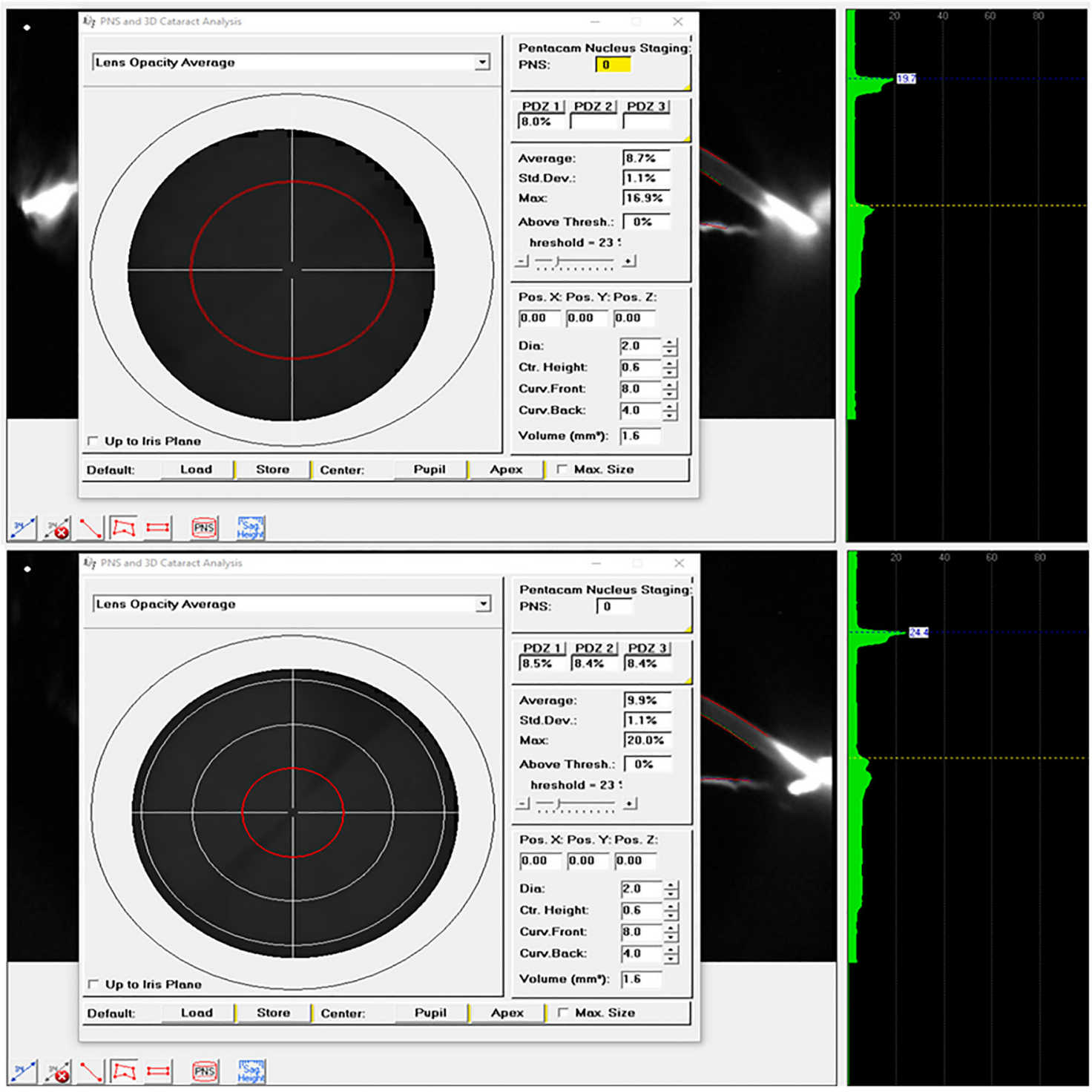

Fig. 2 The crystalline lens densitometry measurements of patients in VKC (upper figure) and healthy control (lower figure) group were depicted 
between the groups was performed using Student's t test or the Mann-Whitney U test. A p-value $<0.05$ was considered statistically significant.

\section{Results}

Demographic and ophthalmic features

In total, 109 eyes were included in the study; of those, 51 were in the VKC group. The VKC group contained 35 males (16 females), and the control group comprised 22 males (36 females). The mean age was $17.5 \pm 4.1$ years (range 12-30 years) for the VKC group and $18.4 \pm 5$ years (range 10-25 years) for the control group. Both groups were statistically age- and gender-matched ( $\mathrm{p}=0.08, \mathrm{p}=0.63$, respectively). The mean BCVA was $0.96 \pm 0.06$ in the VKC group and $0.97 \pm 0.06$ in the control group $(p=0.44)$. None of the participants in either the study group or the control group had visible corneal scarring. No abnormal fluorescein staining of the corneal surface or peripheral corneal neovascularization was observed in any participants. The crystalline lens was subjectively evaluated as clear in all participants. The mean IOP was $14.4 \pm 2.9$ in the VKC group and $13.8 \pm 2.8$ in the control group $(\mathrm{p}=0.23)$ (Table 1$)$.

Keratometry and anterior chamber measurements

The mean anterior $\mathrm{K}_{\text {mean }}$ and posterior $\mathrm{K}_{\text {mean }}$ values were $43 \pm 1.5 \mathrm{D}$ and $6.32 \pm 0.25 \mathrm{D}$ in the $\mathrm{VKC}$ group and $43.2 \pm 1.05 \mathrm{D}$ and $6.27 \pm 0.22 \mathrm{D}$ in the control group, respectively ( $p=0.53$ and 0.3 , respectively, by
Student's t test). The mean anterior corneal astigmatism and posterior corneal astigmatism were $1.2 \pm 1$ $\mathrm{D}$ and $0.37 \pm 0.16 \mathrm{D}$ in the VKC group, and $0.93 \pm 0.54 \mathrm{D}$ and $0.3 \pm 0.13 \mathrm{D}$ in the control group, respectively $(\mathrm{p}=0.08$ and $\mathrm{p}=0.02$, respectively, by the Mann-Whitney U test). A statistically significant difference was noted between the groups in terms of posterior corneal astigmatism $(p=0.02)$. The mean corneal pachymetry, $\mathrm{CV}, \mathrm{ACD}, \mathrm{ACA}$, and ACV were similar in both groups $(\mathrm{p}=0.63, \mathrm{p}=0.26, \mathrm{p}=0.60$, $\mathrm{p}=0.41$, and $\mathrm{p}=0.32$, respectively) (Table 2 ).

Corneal and crystalline lens densitometry measurements

The total mean corneal densitometry values in the zones extending from $6-10 \mathrm{~mm}$ and from $10-12 \mathrm{~mm}$ were higher in the VKC group than in the control group ( $\mathrm{p}=0.04$ and $\mathrm{p}=0.012$, respectively). Analysis of the corneal density according to the depth of the cornea revealed a higher level of backscatter in the anterior $120 \mu \mathrm{m}$ layer in the zones extending from 6-10 $\mathrm{mm}$ and $10-12 \mathrm{~mm}$ in the VKC group compared to the controls $(\mathrm{p}=0.011$ and $\mathrm{p}<0.001$, respectively, by the Mann-Whitney U test). The mean crystalline lens was denser in the VKC group than in the control group $(8.96 \pm 1.6$ vs. $8.5 \pm 0.57$, respectively, $\mathrm{p}=0.04$, by Student's t test) (Table 3).

\section{Discussion}

VKC is a chronic recurrent inflammatory ocular surface disease that can lead to certain corneal

Table 1 Demographic and ophthalmologic features of both groups

\begin{tabular}{|c|c|c|c|c|c|c|c|}
\hline \multirow[t]{2}{*}{ Demographic features } & \multicolumn{2}{|l|}{$\mathrm{VKC}$} & \multicolumn{3}{|c|}{ Control } & \multirow[t]{2}{*}{$p$ value } & \\
\hline & Mean & SD & Mean & & SD & & \\
\hline Age (years) & 17.5 & 4.1 & & 18.4 & 5 & & 0.08 \\
\hline \multirow[t]{3}{*}{ Gender $(\mathrm{M} / \mathrm{F})$} & $25 / 26$ & & $22 / 36$ & & & 0.24 & \\
\hline & $\mathrm{VKC}$ & & Control & & & P-value & \\
\hline & Mean & SD & Mean & & SD & & \\
\hline BCVA (decimal) & 0.96 & 0.06 & 0.97 & & 0.06 & 0.44 & \\
\hline IOP (mmHg) & 14.4 & 2.9 & & 13.8 & 2.8 & & 0.23 \\
\hline
\end{tabular}

$V K C$, Vernal keratoconjunctivitis; $S D$ : Standard deviation; $M$, Male; $F$, Female; $B C V A$, Best-corrected visual acuity; IOP, Intraocular pressure 
Table 2 The keratometric and anterior segment features of both groups and comparison analysis

\begin{tabular}{|c|c|c|c|c|c|}
\hline \multirow[t]{2}{*}{ Keratometric values } & \multicolumn{2}{|l|}{ VKC } & \multicolumn{2}{|c|}{ Control } & \multirow[t]{2}{*}{$p$ value } \\
\hline & Mean & SD & Mean & SD & \\
\hline \multicolumn{6}{|l|}{ Anterior curvature } \\
\hline Kmean (D) & 43.1 & 1.5 & 43.2 & 1.06 & 0.22 \\
\hline Astigmatism & 1.2 & 1 & 0.9 & 0.53 & 0.08 \\
\hline \multicolumn{6}{|l|}{ Posterior curvature } \\
\hline Kmean (D) & 6.31 & 0.25 & 6.27 & 0.22 & 0.42 \\
\hline Astigmatism & 0.36 & 0.15 & 0.29 & 0.13 & $0.02 *$ \\
\hline \multirow[t]{2}{*}{ AS features } & $\mathrm{VKC}$ & & Contro & & $p$ value \\
\hline & Mean & SD & Mean & SD & \\
\hline Pachymeter $(\mu \mathrm{m})$ & 540 & 33 & 543 & 28 & 0.63 \\
\hline Corneal volume $(\mu \mathrm{L})$ & 61.7 & 4.05 & 60.9 & 3.26 & 0.26 \\
\hline AC depth (mm) & 3.13 & 0.22 & 3.10 & 0.24 & 0.60 \\
\hline AC volume $(\mu \mathrm{L})$ & 183.4 & 25.9 & 188.3 & 24.7 & 0.41 \\
\hline AC angle (Degree) & 38.9 & 5.1 & 39.7 & 5.6 & 0.32 \\
\hline
\end{tabular}

$\overline{V K C}$, Vernal keratoconjunctivitis; $D$, Diopter; $S D$, Standard deviation; $A S$, Anterior segment, $\mu m$, micrometer; $\mu L$, Microliter; $A C$, Anterior chamber

${ }^{*} p<0.05$

pathologies, such as keratoconus and limbal deficiency [10]. A combination of persistent mechanical trauma and destruction of the corneal structure by inflammatory cells is suspected in the pathogenesis of these complications [3]. We evaluated the corneal and lens densitometry along with anterior chamber dimensions and keratometric readings in a group of patients with tarsal VKC. We have compared the acquired data with healthy age- and gender-matched controls.

Posterior corneal astigmatism has become a popular area of study in recent years due to its effect on visual outcomes after toric intraocular lens implantation and refractive surgeries [24, 25]. Previous studies have reported average posterior corneal astigmatism values between -0.26 and -0.78 diopter [26, 27]. To date, however, no study has evaluated posterior corneal astigmatism in VKC patients. Chan TCY et al. found a greater prevalence of anterior higherorder aberrations in patients with VKC than in healthy subjects [15]. The anterior corneal astigmatism was also higher in the patients with VKC than in the control group in our study, but the difference did not reach statistical significance $(\mathrm{p}=0.08)$. Henriquez MA et al. found an increase in posterior corneal astigmatism in keratoconus eyes due to an eye-rubbing effect [28]. Our study found that posterior corneal astigmatism was significantly greater in patients with VKC than in healthy controls. This outcome might also have reflected an increased eye-rubbing habit of the participants in the study group. Conversely, the previous authors also showed significantly greater changes in $\mathrm{ACV}$ and IOP in the keratoconus group than in the control group, in addition to the posterior corneal astigmatism after eye rubbing [28]. Our study found no statistically significant differences between the two groups in terms of corneal and anterior segment dimensions (mean corneal pachymetry, CV, ACD, ACA, and ACV) or in the mean IOP. Hence, we believe that the increased posterior corneal astigmatism is an indicator of $\mathrm{VKC}$ rather than an indirect sign of an eye-rubbing habit.

The hydration state and a regular alignment of collagen fibrils in the cornea are the crucial aspects that maintain its transparency [29]. The light backscattering within the corneal tissue is minimal in a transparent and healthy cornea [30]; however, light backscattering is higher in the anterior $120 \mu \mathrm{m}$ portion of the optically transparent cornea than in the deeper portions in healthy individuals. This outcome is explained by the lower degree of corneal lamellar organization in the anterior stroma than in the posterior stroma and the intensity of the keratocyte presence in the superficial stroma [31,32]. The corneal light backscattering is considered an indicator of corneal health; therefore, several studies have been conducted to determine the early subclinical alterations that occur in various ocular diseases [16][19, 33, 34].

We observed greater corneal densitometry in the peripheral anterior cornea of patients with VKC than in the controls. The corneal density would likely increase due to the loss of transparency of the cornea. In vivo corneal microscopy showed the infiltration of the epithelial and anterior stromal layers with inflammatory cells in VKC [14]. This cellular infiltration of the cornea could only be possible via the limbal vessel route; therefore, observing an increase in the peripheral corneal densitometry readings would not be surprising in patients with VKC. The disruption of the collagen matrix and swelling of the peripheral cornea due to the inflammatory response and cell infiltration via the limbal vessels might have played a role in this outcome in the patients with VKC [35]. 
Table 3 The corneal and crystalline lens densitometry comparison between the VKC and the control group
$V K C$, Vernal

keratoconjunctivitis; $S D$,

Standard deviation; $\mathrm{mm}$ : millimeter

$* p<0.05$

\begin{tabular}{|c|c|c|c|c|c|}
\hline \multirow[t]{2}{*}{ Corneal densitometry } & \multicolumn{2}{|l|}{ VKC } & \multicolumn{2}{|l|}{ Control } & \multirow[t]{2}{*}{$p$ value } \\
\hline & Mean & SD & Mean & SD & \\
\hline \multicolumn{6}{|l|}{ Anterior layer } \\
\hline $0-2 \mathrm{~mm}$ & 19.8 & 4.05 & 19.4 & 1.22 & 0.96 \\
\hline $2-6 \mathrm{~mm}$ & 17.7 & 2.38 & 17.6 & 1.10 & 0.80 \\
\hline $6-10 \mathrm{~mm}$ & 18.5 & 4.34 & 16.6 & 2.11 & $0.01 *$ \\
\hline $10-12 \mathrm{~mm}$ & 32.5 & 10.83 & 24.2 & 5.47 & $<0.001 *$ \\
\hline \multicolumn{6}{|l|}{ Central layer } \\
\hline $0-2 \mathrm{~mm}$ & 15.8 & 2.21 & 15.3 & 0.75 & 0.16 \\
\hline $2-6 \mathrm{~mm}$ & 13.7 & 1.55 & 13.5 & 0.64 & 0.68 \\
\hline $6-10 \mathrm{~mm}$ & 13.4 & 1.90 & 13.0 & 1.45 & 0.15 \\
\hline $10-12 \mathrm{~mm}$ & 20.3 & 4.91 & 19.6 & 3.78 & 0.54 \\
\hline \multicolumn{6}{|l|}{ Posterior layer } \\
\hline $0-2 \mathrm{~mm}$ & 12.6 & 1.11 & 12.4 & 0.61 & 0.21 \\
\hline $2-6 \mathrm{~mm}$ & 11.1 & 0.99 & 11.0 & 0.51 & 0.68 \\
\hline $6-10 \mathrm{~mm}$ & 11.0 & 1.13 & 11.0 & 0.98 & 0.64 \\
\hline $10-12 \mathrm{~mm}$ & 14.1 & 2.94 & 15.1 & 3.00 & 0.06 \\
\hline \multicolumn{6}{|l|}{ Total } \\
\hline $0-2 \mathrm{~mm}$ & 16.1 & 2.32 & 15.7 & 0.76 & 0.37 \\
\hline $2-6 \mathrm{~mm}$ & 14.2 & 1.57 & 14.1 & 0.67 & 0.81 \\
\hline $6-10 \mathrm{~mm}$ & 14.3 & 2.30 & 13.5 & 1.47 & $0.04 *$ \\
\hline $10-12 \mathrm{~mm}$ & 22.1 & 5.70 & 19.5 & 3.81 & $0.01 *$ \\
\hline \multirow[t]{2}{*}{ Lens densitometry } & $\mathrm{VKC}$ & & Control & & $p$ value \\
\hline & Mean & SD & Mean & SD & \\
\hline Total & 8.96 & 1.61 & 8.50 & 0.57 & $0.04 *$ \\
\hline
\end{tabular}

One retrospective comparative study reported that the backward scattering in both the anterior and posterior layers of the central $6 \mathrm{~mm}$ part of the cornea was greater in patients with VKC than in healthy individuals [15]. The explanations given for these results were the repeated mechanical microtrauma on the central cornea caused by eye-rubbing and protruding papillary structures on the tarsal conjunctiva. However, no further analysis was conducted on peripheral corneal density in the cohort of that study, nor were any possible mechanisms suggested for the sparing of the central corneal layer in the cohort. Most recently, Çağlayan $\mathrm{M}$ et al. evaluated the corneal densitometry of VKC patients with different clinical grades. They have found an increased peripheral corneal densitometry in moderate-to-severe cases compared to healthy controls. In contrast to our study, they have included a heterogeneous group of VKC cases [20].

The corneal backward scattering level tended to be higher and more widespread through the corneal layers with advancing disease severity of keratoconus [36]. Therefore, we can speculate that the degenerative process progressed throughout the corneal layers during the course of the disease. In support of this speculation, a comparative study comprising subclinical keratoconus patients and healthy controls reported significantly higher corneal density in all central zone layers and in the anterior and central layers of the 0-6 mm zone in the keratoconus group [34]. However, not all patients with VKC develop keratoconus (14-27\%); therefore, no direct comparison can be made between our results and those of the earlier study [12]. We did not observe any abnormal fluorescein staining of the corneal epithelium or any visible peripheral neovascularization in our patients with $\mathrm{VKC}$, and we explained our results as indicating the presence of a subclinical degeneration of the limbal area in these patients. Limbal stem cell deficiency, vernal pseudogerontoxon, and peripheral corneal neovascularization are known secondary 
complications of VKC [1]. In vivo confocal biomicroscopy evaluation of the limbal area of patients with VKC would therefore be warranted to confirm this possibility.

Our evaluation of the lens densitometry results for the same group of patients with VKC is the second in the literature. We found a significantly greater total lens density in patients with VKC than in normal subjects. Çağlayan $\mathrm{M}$ et al. have also found increased lens densitometry in clinically moderate and severe VKC cases [20]. Even in patients who had been medication off for three months before participating in the study, the repeated usage of steroid-containing eye drops during the active phase of VKC could have led to this outcome.

Our study's strengths are its large sample size and its specific selection of VKC cases with only tarsal involvement and completely normal corneal topography. Although we excluded subjects with severe dry eye disease and patients with other corneal disorders, the cases with undetected subclinical keratoconus or various degrees of the subtle dry eye might have affected our results [15, 34]. Further studies using in vivo confocal microscopy of the limbal area in VKC cases are needed to support our findings.

Overall, posterior corneal astigmatism was greater in VKC cases than in healthy age- and gender-matched controls. The 6-12 $\mathrm{mm}$ annular zone of the anterior peripheral cornea showed greater corneal density in VKC cases than in healthy subjects. The lens clarity was also subclinically lower in the VKC cases than in the control cases, probably due to the repeated use of steroid-containing eye drops during the active phase of VKC.

Authors' contribution Y.C.Y and S.C.I performed the data collection; M.D.O, S.C.I, and Y.C.Y planned the work, designed the figures and tables, conducted the statistical analysis, and wrote the paper.

Funding No commercial relationship exists for any of this article's authors in the form of financial support or personal financial interest.

Data availability and materials The data supporting our findings can be found at Agri State Hospital, Ophthalmology Department.

\section{Declarations}

Conflict of interest Authors declare that they have no conflicts of interest.

Consent to publish Written informed consent for publication was obtained from all of the participants.

Ethical approval All procedures performed were in accordance with the 1964 Helsinki declaration and the institutional ethical standards. The Agri State Hospital Ethics Board has approved the study. The consent for participation from all participants and the representatives of children aged below 16 was acquired for the study.

\section{References}

1. Bonini S, Coassin M, Aronni S, Lambiase A (2004) Vernal keratoconjunctivitis. Eye 18(4):345-351

2. Addis H, Jeng B (2018) Vernal keratoconjunctivitis. ClinOphthalmol 12:119-123

3. Leonardi A (2002) Vernal keratoconjunctivitis: pathogenesis and treatment. ProgRetin Eye Res 21(3):319-339

4. Metz D, Hingorani M, Calder V, Buckley R, Lightman S (1997) T-cell cytokines in chronic allergic eye disease. J Allergy ClinImmunol 100(6):817-824

5. Lambiase A et al (2009) Prospective, multicenter demographic and epidemiological study on vernal keratoconjunctivitis: a glimpse of ocular surface in italian population. ophthalmic Epidemiol 16(1):38-41

6. Bonini S et al (2000) Vernal keratoconjunctivitis revisited. Ophthalmology 107(6):1157-1163

7. Saboo U, Sangwan V, Jain M, Reddy J (2013) Demographic and clinical profile of vernal keratoconjunctivitis at a tertiary eye care center in India. Indian J Ophthalmol 61(9):486

8. Cameron JA (1995) Shield ulcers and plaques of the cornea in vernal keratoconjunctivitis. Ophthalmology 102(6):985-993

9. Buckley RJ (1988) Vernal Keratoconjunctivitis. IntOphthalmolClin 28(4):303-308

10. La Rosa M et al (2013) Allergic conjunctivitis: a comprehensive review of the literature. Ital J Pediatr 39(1):18

11. Lapid-Gortzak R, Rosen S, Weitzman S, Lifshitz T (2002) Videokeratography findings in children with vernal keratoconjunctivitis versus those of healthy children. Ophthalmology 109(11):2018-2023

12. Totan Y, Hepşen IFF, Çekiç O, Gündüz A, Aydın E (2001) Incidence of keratoconus in subjects with vernal keratoconjunctivitis. Ophthalmology 108(4):824-827

13. Barreto J, Netto MV, Santo RM, José NK, Bechara SJ (2007) Slit-scanning topography in vernal keratoconjunctivitis. Am J Ophthalmol 143(2):250-254.e1

14. Leonardi A, Lazzarini D, Bortolotti M, Piliego F, Midena E, Fregona I (2012) Corneal confocal microscopy in patients with vernal keratoconjunctivitis. Ophthalmology 119(3):509-515

15. Chan TCY et al (2018) Corneal backward scattering and higher-order aberrations in children with vernal 
keratoconjunctivitis and normal topography. ActaOphthalmol 96(3):e327-e333

16. Tekin $\mathrm{K}$ et al (2017) Objective evaluation of corneal and lens clarity in children with type 1 diabetes Mellitus. Am J Ophthalmol 179:190-197

17. Ramm L, Spoerl E, Pillunat LE, Terai N (2020) Corneal densitometry in diabetes mellitus. Cornea 39(8):968-974

18. Anayol MA, Bostancı B, Şekeroğlu MA, Şimşek M, Günaydın S, Yılmazbaş P (2017) Assessment of corneal densitometry in rheumatoid arthritis patients. TürkOftalmolDerg 47(3): 125-129

19. Doğuizi S, Özateş S, Hoşnut FÖ, Şahin GE, Şekeroğlu MA, Yilmazbaş P (2019) Assessment of corneal and lens clarity in children with Wilson disease. J Am AssocPediatrOphthalmol Strabismus 23(3):147.e1-147.e8

20. Çağlayan M, Öncül H, Alakus MF, Dag U (2021) Corneal and lens densitometry with Pentacam HR in children with vernal keratoconjunctivitis. ClinExpOptom 104(2):156-161

21. American Academy of Ophthalmology, "Important coronavirus updates for ophthalmologists," Important coronavirus updates for ophthalmologists. [Online]. Available: https://www.aao.org/headline/alertimportant-coronaviruscontext.

22. Sacchetti M, Lambiase A, Mantelli F, Deligianni V, Leonardi A, Bonini S (2010) Tailored approach to the treatment of vernal keratoconjunctivitis. Ophthalmology 117(7):1294-1299

23. Otri AM, Fares U, Al-Aqaba MA, Dua HS (2012) Corneal Densitometry as an indicator of corneal Health. Ophthalmology 119(3):501-508

24. Reitblat O, Levy A, Kleinmann G, Abulafia A, Assia EI (2016) Effect of posterior corneal astigmatism on power calculation and alignment of toric intraocular lenses: comparison of methodologies. J Cataract Refract Surg 42(2):217-225

25. Ambrósio R et al (2013) enhanced screening for ectasia susceptibility among refractive candidates: the role of corneal tomography and biomechanics. CurrOphthalmol Rep 1(1):28-38
26. Lowry EA et al (2019) The effect of anterior corneal astigmatism orientation on toric intraocular lens outcomes. Open J Ophthalmol 09(02):84-93

27. Mohammadi S-F, Khorrami-Nejad M, Hamidirad M (2019) Posterior corneal astigmatism: a review article. ClinOptom 11:85-96

28. Henriquez MA, Cerrate M, Hadid MG, Cañola-Ramirez LA, Hafezi F, Izquierdo L (2019) Comparison of eye-rubbing effect in keratoconic eyes and healthy eyes using Scheimpflug analysis and a dynamic bidirectional applanation device. J Cataract Refract Surg 45(8):1156-1162

29. O'Donnell C, Wolffsohn JS (2004) Grading of corneal transparency. Contact Lens Anterior Eye 27(4):161-170

30. Ní Dhubhghaill S, Rozema JJ, Jongenelen S, Ruiz Hidalgo I, Zakaria N, Tassignon M-J (2014) Normative values for corneal densitometry analysis by scheimpflug optical assessment. Investig Opthalmol Vis Sci 55(1):162

31. Ruberti JW, Sinha Roy A, Roberts CJ (2011) Corneal Biomechanics and Biomaterials. Annu Rev Biomed Eng 13(1):269-295

32. Patel S, McLaren J, Hodge D, Bourne W (2001) Normal human keratocyte density and corneal thickness measurement by using confocal microscopy in vivo. Invest Ophthalmol Vis Sci 42(2):333-339

33. Kumar DA, Agarwal A, Jaganathasamy N (2020) Densitometry analysis of corneal backscatter after pre-descemet endothelial keratoplasty for pseudophakic bullous keratopathy. Cornea 39(1):30-38

34. Koc M et al (2018) An early finding of keratoconus: increase in corneal densitometry. Cornea 37(5):580-586

35. Kumagai N, Fukuda K, Fujitsu Y, Yamamoto K, Nishida T (2006) Role of structural cells of the cornea and conjunctiva in the pathogenesis of vernal keratoconjunctivitis. ProgRetin Eye Res 25(2):165-187

36. Lopes B, Ramos I, Ambrósio R (2014) Corneal densitometry in keratoconus. Cornea 33(12):1282-1286

Publisher's Note Springer Nature remains neutral with regard to jurisdictional claims in published maps and institutional affiliations. 